\title{
UGT1A1 Mutation Association with Increased Bilirubin Levels and Severity of Unconjugated Hyperbilirubinemia in ABO Incompatible Newborns of China
}

\section{Hui Yang}

Yangtze University

Fen Lin

Chaozhou central hospital

\section{Zikai Chen}

Hanshan Normal University

\section{Lin Zhang}

Chaozhou central hospital

JiaXin Xu

Chaozhou central hospital

\section{YongHao Wu}

Chaozhou central hospital

\author{
JingYing Gu \\ Chaozhou central hospital
}

\section{YuBin Ma}

Chaozhou central hospital

JianDong Li

Chaozhou central hospital

Liye Yang ( $\nabla$ yangleeyee@sina.com)

Chaozhou Central Hospital https://orcid.org/0000-0003-1581-9089

\section{Research article}

Keywords: Neonatal, Uridine diphosphate glucuronosyltransferase isoenzyme

Posted Date: January 8th, 2021

DOI: https://doi.org/10.21203/rs.3.rs-33510/v1

License: (c) (i) This work is licensed under a Creative Commons Attribution 4.0 International License. Read Full License 


\section{Abstract}

Background: Neonatal hyperbilirubinemia causing jaundice is common in East Asian population. Uridine diphosphate glucuronosyltransferase isoenzyme (UGT1A1) glucuronidates bilirubin and converts the toxic form of bilirubin to its nontoxic form.

Method: A retrospective study was conducted to review clinical information of $A B O$ hemolysis neonates (ABO HDN) admitted to the Department of Neonatology, referred for neonatal hyperbilirubinemia, in a large general hospital of southern China from 2011 to 2017. Variation status of UGT1A1 was determined by direct sequencing or genotype assays.

Result: Sixty-nine ABO HDNs were included into the final analysis. UGT1A1 c.211 G>A mutation (UGT1A1*6, p.Arg71Gly, rs4148323) was significantly associated with the increased bilirubin level in ABO HDNs, after adjusted by age, sex and feeding method ( $P=0.019$ for TBIL, $P=0.021$ for IBIL). Moreover, heterozygous and/or homozygous UGT1A1 mutations in the coding sequence region were significantly associated with the increased risk of developing hazardous hyperbilirubinemia (as defined by TSB $>427 \mathrm{umol} / \mathrm{L}$ ) as compared those with a normal UGT1A1 genotype (ORadj=9.16, 95\% Cl 1.99-42.08, $P=0.002$ ) in the study cohort.

Conclusion: UGT1A1 variant in coding region is actively involved in the pathogenesis of $A B O$ hemolysis related neonatal hyperbilirubinemia. Genetic assessment of UGT1A1 may be useful for clinical diagnosis of neonatal unconjugated hyperbilirubinemia.

\section{Background}

Neonatal hyperbilirubinemia causing jaundice is a complex pediatric disorder affecting up to $80 \%$ of newborns worldwide. ${ }^{1,2}$ Although it is benign in the vast majority of infants, total serum bilirubin (TSB) may accumulate and reach very high levels in some cases. Once it reaches the hazardous threshold levels, certain brain regions can be irreversibly damaged. ${ }^{3-5}$

In 2004, the American Academy of Pediatrics (AAP) guidelines listed the East Asia, including mainland China as a major risk factor for severe hyperbilirubinemia. ${ }^{6}$ The incidence and severity of neonatal hyperbilirubinemia in Asians and American Indians are much higher, as compared to those in Caucasian and black populations. It has been suggested that the high incidence rate of hemolytic anemia, caused by $\mathrm{ABO}$ alloimmunizationorglucose-6-phosphate dehydrogenase (G6PD) deficiency, may predispose these populations to neonatal hyperbilirubinemia. The overall risk dramatically increased for a TSB level of $20 \mathrm{mg} / \mathrm{dL}(342 \mathrm{mmol} / \mathrm{L}) .^{7}$

Congenital variation of the bilirubin clearance rate in the liver is also the biological basis of neonatal hyperbilirubinemia risk in Asia. The key bilirubin metabolism gene, namely, the hepatic bilirubin conjugating isoenzyme UDP glucuronosyltransferase family 1 member A1 (UGT1A1) was classically described for Crigler-Najjar type I and II

syndrome as well as Gilbert syndrome. ${ }^{8-10}$ More and more evidence has shown that the genetic variation of UGT1A1 is also closely related to the incidence rate and severity of neonatal hyperbilirubinemia. ${ }^{10-14}$ However, the innate variants of the UGT1A1 gene are under-diagnosed in neonates and under-recognized as a cause of severe hyperbilirubinemia clinically.

In our previous studies, ${ }^{14,15}$ we have demonstrated the role of UGT1A1 in non-hemolytic unconjugated hyperbilirubinemia in Chinese newborns. Here, we aim to further explore the role of UGT1A1 variants in ABO hemolytic disease of newborns (ABO HDNs). We suspected that ABO HDNs that carried the gene variant for Gilbert's syndrome 
may have a higher risk of developing severe hyperbilirubinemia. This study may enhance our understanding of the genetic basis of neonatal hyperbilirubinemia in Asia.

\section{Methods}

\section{Participants and sample collection}

This retrospective study was conducted in the pediatric center of Chaozhou Central Hospital affiliated to Southern Medical University, Chaozhou, China. All neonates enrolled in this study were admitted to the study center from 2011 to 2017. The neonatal data of all cases were retrospectively analyzed, including date of birth, gender, weight at birth, mode of delivery, gestational age, feeding mode, the TSB level, and the bilirubin peak level before phototherapy.

The eligible infants were full-term newborns with symptomatic ABO hemolytic disease confirmed by a direct Coombs test. Newborns with birth weight less than $2500 \mathrm{~g}$ and gestational age less than 37 weeks were excluded. In addition, the infants who had the following conditions were also excluded: maternal diabetes, infection, Rh incompatibilitycaused hemolytic disease, asphyxia, G6PD deficiency, hypothermia, drug treatment, cerebral hematoma, dehydration, metabolic diseases, hypothyroidism, liver disease, and major organ abnormalities. These conditions were determined by past and family history, as well as clinical and laboratory tests. The information was reviewed and retrieved from the electronic medical records. After clinical diagnosis, the EDTA anticoagulant whole blood samples were collected prospectively and stored at $-20^{\circ} \mathrm{C}$ prior to UGT1A1 genotyping.

This study was initially approved by the Ethics Committee of Chaozhou Central Hospital in 2011 (No. 2011021), and then the second ethical approval was obtained in 2015. As the patients data were analyzed anonymously, and the blood samples in this study were used after the clinical diagnosis (blood routine examination), a waiver of written consent was approved by the Committee.

\section{Dna Extraction And Ugt1a1 Genotyping}

Genomic DNA from peripheral blood specimens was extracted with FlexiGene DNA Kit (Qiagen Inc, Valencia, California). The DNA sequences of promoter, exons, and exon-intron boundaries of UGT1A1 were determined by polymerase chain reaction (PCR) and DNA sequencing as previously described. ${ }^{14}$ The repetitive polymorphism of (TA)n in the promoter region was further confirmed by capillary electrophoresis, described in detail in our previous studies. ${ }^{14}$, 15

\section{Data analysis}

Hardy-Weinberg equilibrium (HWE) was used to test the two common variants of UGT1A1 locus. Linkage disequilibrium (LD) analysis for the polymorphisms within UGT1A1 was performed, and the haplotypes were inferred using the web tool SNPStats (http://bioinfo.iconcologia.net/SNPStats), ${ }^{16}$ as described in our previous studies ${ }^{14,15}$.

The differences of categorical variables between the two groups were compared by chi-square test or Fisher exact test. According to the UGT1A1 genotype, all infants were divided into two (wild type and mutant) or three groups (wild type, heterozygous mutant, and homozygous mutant). Independent group t-test was used to analyze the difference of continuous variables if the dataset was normally distributed; otherwise, the Mann-Whitney test was used. 
After adjusting for known clinical risk factors for neonatal hyperbilirubinemia (including gender, breastfeeding, and age), a linear regression model was used to assess the association between specific polymorphisms or haplotypes of UGT1A1 and the TSB peak values prior to phototherapy. According to the AAP guidelines, all the infants were divided into the hazardous group (TSB $\geq 427 \mu \mathrm{mol} / \mathrm{L}$ ), the severe group (TSB $\geq 342 \mu \mathrm{mol} / \mathrm{L}$ ), and the non-severe group (TSB < $342 \mu \mathrm{mol} / \mathrm{L}$ ). Then logistic regression was used to evaluate the association of the UGT1A1 gene variations with the severity of hyperbilirubinemia.

All statistical analyses were performed using the two-sided test by SPSS (version 16) and SNPstat, and P $<0.05$ was considered as statistically significant.

\section{Results}

\section{Clinical analysis}

After excluding neonates with the conditions described above, a total of 69 full-term ABO HDNs infants were admitted to the hospital on the 3rd day after birth (range, 1-10 days). The average peak serum total serum bilirubin level (TBIL) was $335.1 \mu \mathrm{mol} / \mathrm{L}(123.3-652.1 \mu \mathrm{mol} / \mathrm{L})$. Among 69 ABO HDNs, 31 cases had peak TSB $\geq 342 \mu \mathrm{mol} / \mathrm{L}$, in which 15 neonates had TSB $\geq 427 \mu \mathrm{mol} / \mathrm{L}$. All the neonates received phototherapy. Most of the neonates were discharged without complication, except for two infants with bilirubin encephalopathy symptoms.

There were significant differences in the bilirubin levels, but no differences in average gestational age, birth weight, gender and feeding pattern between the two groups of neonates divided according to the c. 211 genotypes of UGT1A1 - the most common UGT1A1 variant in Asian population (Table 1). 
Table 1

Demographic and clinical features among the neonates with $A B O$ hemolytic disease (ABO HDN) in UGT1A1 c. $211 \mathrm{G}>$ A mutation group VS c.211 normal group $(\mathrm{N}=69)$.

\begin{tabular}{|c|c|c|c|}
\hline & c.211 mutation/ABO HDN & c.211 normal /ABO HDN & $P$ \\
\hline Sex & & & NS \\
\hline Male & $6(30.0)$ & $25(51.0)$ & \\
\hline female & $14(70.0)$ & $24(49.0)$ & \\
\hline Gestational week & $39.42 \pm 0.23$ & $39.24 \pm 0.13$ & NS \\
\hline Birth weight(kg) & $3.30 \pm 0.076$ & $3.19 \pm 0.056$ & NS \\
\hline \multicolumn{4}{|c|}{$\begin{array}{l}\text { Peak serum bilirubin levels } \\
\text { (umol/L) }\end{array}$} \\
\hline TBIL & $404.15(219.02-556.07)$ & $315.00(145.8-585.2)$ & 0.028 \\
\hline IBIL & $380.70(201.04-527.73)$ & $303.10(128.85-552.05)$ & 0.037 \\
\hline DBIL & $14.30(4.88-69.07)$ & $12.08(3.30-35.20)$ & NS \\
\hline Feeding & & & NS \\
\hline Breast fed & $3(15.0)$ & $11(22.4)$ & \\
\hline Breast and formula & $2(10.0)$ & $9(18.4)$ & \\
\hline Formula & 14(70.0) & $20(40.8)$ & \\
\hline unknown & $1(5.0)$ & $9(18.4)$ & \\
\hline Delivery method & & & NS \\
\hline Vaginal & $7(35.0)$ & $27(55.1)$ & \\
\hline Cesarean & $13(65.0)$ & $22(44.9)$ & \\
\hline \multicolumn{4}{|c|}{ Data are presented as $\mathrm{n}(\%)$, mean standard deviation, or median (95\% Confidence Interval). } \\
\hline NS: no significanc & & & \\
\hline
\end{tabular}

\section{Ugt1a1 Variant Results}

In addition to the two common variants of UGT1A1 gene, TA7 polymorphism (UGT1A1*28, rs 8175347 ) in the promoter and c.211 G > A mutation (UGT1A1*6, p.Arg71Gly, rs4148323) in exon 1, another coding variant c. 1091C > T (UGT1A1*73, p.Pro364Leu, rs34946978) was observed in the neonates. Specifically, heterozygote of TA7 promoter polymorphism (TA6/TA7) was detected in 9 neonates, with no homozygote for TA7 polymorphism (TA7/TA7) observed. The frequency of heterozygous (G/A) and homozygous (A/A) genotypes of c.211 G > A mutation were 0.275 $(19 / 69)$ and 0.014 (1/69), respectively. Three cases were observed with heterozygous c.1091C > T mutation (Table 2). 
Table 2

Minor allelic, genotypic, and haplotype distributions of UGT1A1 polymorphism in studied patients $(\mathrm{N}=69)$.

\begin{tabular}{|c|c|c|c|c|}
\hline UGT1A1 polymorphism & Location & $\mathbf{N}$ & Frequency & $P_{\mathrm{H}-\mathrm{W}}{ }^{*}$ \\
\hline TATA box(rs8175347) & promoter & & & 1 \\
\hline TA7 & & 9 & 0.07 & \\
\hline TA6 & & 129 & 0.93 & \\
\hline TA7/TA7 & & 0 & 0 & \\
\hline TA6/TA7 & & 9 & 0.13 & \\
\hline TA6/TA6 & & 60 & 0.87 & \\
\hline C. $211 \mathrm{G}>\mathrm{A}(\mathrm{rs} 4148323)$ & Exon 1 & & & 1 \\
\hline A & & 21 & 0.15 & \\
\hline G & & 117 & 0.85 & \\
\hline AVA & & 1 & 0.01 & \\
\hline$G / A$ & & 19 & 0.28 & \\
\hline G/G & & 49 & 0.71 & \\
\hline c.1091 C > T(rs34946978) & Exon 4 & & & 1 \\
\hline $\mathbf{T}$ & & 3 & 0.02 & \\
\hline C & & 135 & 0.98 & \\
\hline $\mathrm{T} / \mathrm{T}$ & & 0 & 0 & \\
\hline $\mathrm{C} / \mathrm{T}$ & & 3 & 0.04 & \\
\hline $\mathrm{C} / \mathrm{C}$ & & 66 & 0.96 & \\
\hline \multicolumn{5}{|c|}{ Haplotype(rs8175347-rs4148323-rs34946978) } \\
\hline TA6GC & & & 0.76 & \\
\hline TA6AC & & & 0.15 & \\
\hline TA7GC & & & 0.065 & \\
\hline TA6GT & & & 0.018 & \\
\hline TA6AT & & & 0.0037 & \\
\hline
\end{tabular}

There was a strong pairwise LD between the UGT1A1 promoter polymorphism and exon mutation (|D|'>0.8), but none of the polymorphisms in our study had a statistically significant deviation in the HWE test. Haplotype analysis showed that the TA6GC (rs8175347-rs4148323-rs34946978) was the predominant haplotype among the study subjects (75.85\%), (Table 2). 


\section{Co-inherited Ugt1a1 Variant On Bilirubin Levels In Abo Hdns}

When analyzing the peak bilirubin levels according to UGT1A1 genotypes, the average peak bilirubin levels (TBIL and indirect serum bilirubin level (IBIL)) of $\mathrm{ABO}(+)$ neonates with both heterozygous and homozygous c.211 $\mathrm{G}>\mathrm{A}$ coding mutation were higher as compared to those with normal UGT1A1 genotype ( $P=0.028$ for TBIL, $P=0.036$ for IBIL), whereas direct serum bilirubin level (DBIL) showed no statistical difference among the three genotypes (Table 1, Fig. 1). No significant difference in bilirubin levels was observed in the presence of either heterozygous of TA7 promoter polymorphism or heterozygous of c.1091C > T mutation in the neonates.

After adjusting the potential covariance (age, gender, and feeding method), c.211 G > A mutation was still associated with the increased bilirubin levels $\left(\mathrm{OR}_{\mathrm{adj}}=78.24,95 \% \mathrm{Cl} 14.68-141.80, P=0.019\right.$ for $\mathrm{TBIL}, \mathrm{OR}_{\mathrm{adj}}=73.26,95 \% \mathrm{Cl} 12.84-$ 133.69, $P=0.021$ for IBIL) (Table 3). Moreover, haplotype association analysis showed that the TA6AC (rs887829rs4148323- rs34946978) was significantly associated with increased bilirubin levels $\left(\mathrm{OR}_{\mathrm{adj}}=84.01,95 \% \mathrm{Cl} 23.2-144.82\right.$, $P=0.009$ for TBIL, $\mathrm{OR}_{\mathrm{adj}}=79.02,95 \% \mathrm{Cl} 21.40-136.64, P=0.009$ for IBIL). Haplotype TA6GT also showed significant association with increased bilirubin levels $\left(\mathrm{OR}_{\mathrm{adj}}=107.89,95 \% \mathrm{Cl} 93.65-122.14, P<0.001\right.$ for TBIL, $\mathrm{OR}$ adj $=107.01,95 \% \mathrm{Cl}$ 93.58-120.44, $P<0.001$ for IBIL) (Table 3). 
Table 3

The associations between serum bilirubin level and different types of UGT1A1 mutation and genotypes adjusted by age, gender, and feeding practice: Line regression analysis $\left(\mathrm{N}=59^{\star}\right)$.

\begin{tabular}{|c|c|c|c|c|}
\hline \multirow[t]{2}{*}{ Genotypes } & \multicolumn{2}{|l|}{ TBIL } & \multicolumn{2}{|l|}{ IBIL } \\
\hline & $\mathrm{OR}_{\mathrm{adj}}^{\dagger}(95 \% \mathrm{Cl})$ & $\mathbf{P}$ & $\mathrm{OR}_{\mathrm{adj}}^{\dagger}(95 \% \mathrm{Cl})$ & $\mathbf{P}$ \\
\hline \multicolumn{5}{|l|}{ TATA box } \\
\hline TA6/TA6 & 0.00 & \multirow[t]{2}{*}{0.57} & 0.00 & \multirow[t]{2}{*}{0.58} \\
\hline TA6/TA7 & $30.04(-73.12-133.19)$ & & 27.55(-70.39-125.49) & \\
\hline \multicolumn{5}{|l|}{$c .211 \mathrm{G}>\mathrm{A}$} \\
\hline$G / G$ & 0.00 & \multirow[t]{2}{*}{0.019} & 0.00 & \multirow[t]{2}{*}{0.021} \\
\hline G/A-A/A & 78.24(14.68-141.80) & & 73.26(12.84-133.69) & \\
\hline \multicolumn{5}{|l|}{ c. $1091 \mathrm{C}>\mathrm{T}$} \\
\hline $\mathrm{C} / \mathrm{C}$ & 0.00 & \multirow[t]{2}{*}{0.16} & 0.00 & \multirow[t]{2}{*}{0.14} \\
\hline $\mathrm{C} / \mathrm{T}$ & 103.06(-39.78-245.90) & & $103.63(-31.65-238.91)$ & \\
\hline \multicolumn{5}{|l|}{ Haplotype $^{\ddagger}$} \\
\hline \multicolumn{5}{|l|}{ (Frequency) } \\
\hline TA6GC(75.85\%) & 0.00 & & 0.00 & \\
\hline TA6AC(16.53\%) & $84.01(23.2-144.82)$ & 0.0092 & 79.02(21.4-136.64) & 0.0097 \\
\hline TA7GC(5.08\%) & $70.42(-26.83-167.68)$ & 0.16 & $65.65(-26.57-157.87)$ & 0.17 \\
\hline TA6GT(2.12\%) & 107.89(93.65-122.14) & $<0.0001$ & 107.01(93.58-120.44) & $<0.0001$ \\
\hline TA6AT(0.42\%) & $149.95(147.33-152.58)$ & $<0.0001$ & $152.42(150.02-154.82)$ & $<0.0001$ \\
\hline \multicolumn{5}{|c|}{ * Ten cases with the feeding practice unknown were not taken into the regression analysis. } \\
\hline \multicolumn{5}{|c|}{${ }^{\dagger}$ Adjusted for age, gender, and feeding practice. } \\
\hline${ }^{\ddagger}$ polymorphisms & in order of: rs8175347 & 148323 & 697 & \\
\hline
\end{tabular}

\section{Co-inherited UGT1A1 variant on severe hyperbilirubinemia risk in ABO HDNs}

The incidence rates of hazardous and severe hyperbilirubinemia in the ABO HDNs were compared in different types of UGT1A1 genotype. Promoter polymorphism and exon mutations were analyzed, separately. Compound heterozygous mutations in the coding sequence were regarded as homozygous mutations. No statistical difference of severe hyperbilirubinemia incidence was found between $\mathrm{ABO}$ HDNs with and without the UGT1A1 mutation $(P>0.05)$. On the contrary, after adjusted by age, gender, and feeding method, ABO HDNs with heterozygous and/or homozygous mutations in the UGT1A1 coding sequence region had a relatively higher risk of developing hazardous hyperbilirubinemia than those with a normal UGT1A1 genotype $\left(\mathrm{OR}_{\mathrm{adj}}=9.16,95 \% \mathrm{Cl} 1.99-42.08, P=0.002\right)$. Moreover, haplotype association analysis showed that TA6AC was significantly associated with a higher incidence of hazardous hyperbilirubinemia in $\mathrm{ABO} \mathrm{HDNs}\left(\mathrm{OR}_{\mathrm{adj}}=9.41,95 \% \mathrm{Cl} 1.80-49.26, P=0.011\right)$ (Table 4). 
Table 4

The associations between risk of severe neonatal hyperbilirubinemia and UGT1A1 coding sequence variants and different type of UGT1A1 haplotype in neonates with ABO hemolysis disease: multivariate logistic regression analysis $\left(\mathrm{N}=59^{*}\right)$.

\begin{tabular}{|c|c|c|c|c|c|c|c|}
\hline \multirow[t]{2}{*}{ Genotype } & \multirow{2}{*}{$\begin{array}{l}\text { Total } \\
\mathrm{N}(\%)\end{array}$} & \multicolumn{3}{|c|}{ TBIL > $342 \mathrm{umol} / \mathrm{L}$} & \multicolumn{3}{|c|}{ TBIL > 427umol/L } \\
\hline & & $N(\%)$ & $\begin{array}{l}\mathrm{OR}_{\mathrm{adj}}^{\dagger} \\
(95 \% \mathrm{Cl})\end{array}$ & $\mathbf{P}$ & $N(\%)$ & $\begin{array}{l}\mathrm{OR}_{\mathrm{adj}}^{\dagger} \\
(95 \% \mathrm{Cl})\end{array}$ & $\mathbf{P}$ \\
\hline \multicolumn{8}{|l|}{ Model $1(n=59)$} \\
\hline Wild type & $38(64.4 \%)$ & $16(57.1 \%)$ & 1.00 & & $4(30.8 \%)$ & 1.00 & \\
\hline $\begin{array}{l}\text { Heterozygous } \\
\text { mutation }\end{array}$ & $19(32.2 \%)$ & $10(35.7 \%)$ & $\begin{array}{l}2.25(0.66- \\
7.61)\end{array}$ & 0.076 & $8(61.5 \%)$ & $\begin{array}{l}8.74(1.86- \\
41.09)\end{array}$ & 0.008 \\
\hline $\begin{array}{l}\text { Homozygous } \\
\text { mutation }\end{array}$ & $2(3.4 \%)$ & $2(7.1 \%)$ & $\begin{array}{l}\text { NA(0.00- } \\
\text { NA) }\end{array}$ & & $1(7.7 \%)$ & $\begin{array}{l}15.09(0.61- \\
375.49)\end{array}$ & \\
\hline \multicolumn{8}{|l|}{ Model $2(n=59)$} \\
\hline Wild type & $38(64.4 \%)$ & $16(57.1 \%)$ & 1.00 & & $4(30.8 \%)$ & 1.00 & \\
\hline $\begin{array}{l}\text { Heterozygous + } \\
\text { Homozygous } \\
\text { mutation }\end{array}$ & $21(35.6 \%)$ & $12(42.9 \%)$ & $\begin{array}{l}2.72(0.82- \\
9.03)\end{array}$ & 0.093 & $9(69.2 \%)$ & $\begin{array}{l}9.16(1.99- \\
42.08)\end{array}$ & 0.002 \\
\hline \multicolumn{8}{|l|}{$\begin{array}{l}\text { Halplotype( } \\
\text { Frequency) }\end{array}$} \\
\hline TA6GC(75.89\%) & & & 1.00 & & & 1.00 & \\
\hline TA6AC(16.58\%) & & & $\begin{array}{l}3.46(0.97- \\
12.39)\end{array}$ & 0.062 & & $\begin{array}{l}9.41(1.80- \\
49.26)\end{array}$ & 0.011 \\
\hline TA7GC(5.08\%) & & & $\begin{array}{l}2.57(0.37- \\
17.89)\end{array}$ & 0.35 & & $\begin{array}{l}8.18(0.80- \\
83.65)\end{array}$ & 0.083 \\
\hline TA6GT(2.17\%) & & & $\begin{array}{l}2.38(0.12- \\
48.13)\end{array}$ & 0.57 & & $\begin{array}{l}10.64(0.44- \\
254.56)\end{array}$ & 0.15 \\
\hline other ${ }^{*}$ & & & - & - & & - & - \\
\hline \multicolumn{8}{|c|}{ * Ten cases with the feeding practice unknown were not taken into the regression analysis } \\
\hline \multicolumn{8}{|c|}{${ }^{\dagger}$ Adjusted for age, gender, and feeding practice. } \\
\hline Other haploty & equenc & in $1 \%$. & & & & & \\
\hline
\end{tabular}

\section{Discussion}

Hyperbilirubinemia is a common disorder among infants. Infants in Asia, including China where hazardous hyperbilirubinemia is not rare ${ }^{1,17}$, are at a greater risk of developing hyperbilirubinemia. $A B O$ incompatibility, one of the main causes of hemolytic disease in newborns, ${ }^{18}$ has been well documented to be associated with the incidence and severity of neonatal hyperbilirubinemia. ${ }^{7,19}$ It is estimated that $27 \%$ of newborns have ABO incompatibility in China, while only $15 \%$ worldwide. ${ }^{20}$ Indeed, ABO hemolytic disease is regarded as an important factor in neonatal hyperbilirubinemia in East Asia. ${ }^{7}$ 
Serum bilirubin level is a function of many factors, which may change the production and excretion of bilirubin. More and more attention has been paid to the role of bilirubin gene polymorphism in the pathogenesis of hyperbilirubinemia. In this study, we demonstrated that UGT1A1 mutation plays an active role in the pathogenesis of ABO hemolysis associated neonatal hyperbilirubinemia. The serum bilirubin level is a consequence of many factors, which may change the production and excretion of bilirubin. Currently, more and more attention has been paid to the contribution of genetic polymorphisms of the bilirubin clearance genes in the pathogenesis of hyperbilirubinemia. In this study, we demonstrated that UGT1A1 mutation and polymorphism play an active role in the pathogenesis of ABO hemolysisrelated neonatal hyperbilirubinemia.

The UGT1A1 coding sequence variant c. $211 \mathrm{G}>\mathrm{A}\left(\mathrm{UGT1A}{ }^{\star} 6\right.$, G71R), the main cause of Gilbert syndrome in East Asia, was also the predominant association factor with high TSB levels and neonatal hyperbilirubinemia risk in the Asian population without any additional icterogenic factors. ${ }^{14,15,21-24}$ In this study, we further confirmed that both the occurrence rate and bilirubin levels of hyperbilirubinemia in the ABO HDNs were significantly higher in the presence of homozygous or heterozygous c.211 mutation. One recent study in Chinese neonates also reported the contribution of c. 211 mutation to neonatal hyperbilirubinemia risk in ABO HDN patients. ${ }^{25}$ However, a similar study in Turkish neonates failed to discern the association of c. 211 variant with the increased hyperbilirubinemia risk in ABO HDNs. ${ }^{26}$ The discrepancy may be due to the fact that the research subjects are from different races and different regions. Large-scale studies across different ethnic groups and regions are necessary to draw further conclusions.

The polymorphism of $(T A)_{n}$ repeat in the UGT1A1 promoter region has also been widely studied. TA7 is common in European and African populations, and it was proposed to be the genetic basis for Gilbert syndrome of Caucasians. ${ }^{27}$ However, increasing studies in China and other countries reported that TA7 promoter polymorphism was not directly related to neonatal hyperbilirubinemia in most Asian regions. ${ }^{21}$ More interestingly, several recent studies in Asian populations, including our previous studies, have shown that heterozygous of TA7 promoter may not cause neonatal hyperbilirubinemia, and may even have a protective effect. ${ }^{14,15,28-30}$ In this study, we also observed that co-expression of TA6 allele, but not TA7, with the exon mutation (rs8175347-rs4148323-rs34946978: TA6AC/TA6GT) in UGT1A1 gene was associated with increased bilirubin levels and neonatal hyperbilirubinemia risk. This finding is contrary to previous studies in Caucasian populations and also inconsistent with the findings in Turkish neonates. ${ }^{26}$ The reason for this contradictory effect of the UGT1A1 promoter polymorphism in serum bilirubin level and neonatal hyperbilirubinemia risk is yet unknown.

Another coding sequence variants, UGT1A1*73(c.1091C > T, p.Pro364Leu, rs34946978), has also been reported to be linked to a significant decrease in UGT1A1 enzyme activity and the severity of Gilbert's syndrome in both Caucasian and Asia populations. ${ }^{31,32}$ Although only the heterozygous c. $1091 \mathrm{C}>\mathrm{T}$ variant was identified in the present study, it has shown to increase bilirubin levels and hyperbilirubinemia risk in ABO HDNs in combination with other variant alleles of UGT1A1 genes (Table 3, Table 4).

There were several limitations in this study. Firstly, the size of the cohort was small, which may be the reason that some analyses could not reach statistical significance. Secondly, the newborns were all from one hospital in China. A larger multi-center study is necessary for future studies. Thirdly, it may not be comprehensive to analyze UGT1A1 alone. Evaluation of additional genes may also help to assess the genetic causes of unconjugated hyperbilirubinemia in newborns.

\section{Conclusion}


Our study demonstrated that UGT1A1 variants contributed to the increased bilirubin level and risk of developing hazardous neonatal hyperbilirubinemia in $\mathrm{ABO} \mathrm{HDNs}$. It is actively involved in the pathogenesis of $\mathrm{ABO}$ hemolysisrelated unconjugated hyperbilirubinemia. This association may caution clinicians to assess UGT1A1 variations for neonates with $\mathrm{ABO}$ hemolysis, and may aid in the identification of high-risk population, which is important for management and intervention of hazardous hyperbilirubinemia.

\section{Abbreviations}

ABO HDNs

ABO hemolytic disease of newborns

UGT1A1

Uridine diphosphoglucuronosyl transferase $1 \mathrm{~A} 1$

TSB

Total serum bilirubin level

TBIL

Total serum bilirubin level

DBIL

Direct serum bilirubin level

IBIL

Indirect serum bilirubin level

\section{Declarations}

\section{Ethics approval and consent to participate}

Ethical approval: All procedures performed in studies involving human participants followed the ethical standards of the study hospital and/or national research committee and with the 1964 Helsinki declaration and its later amendments or comparable ethical standards.

Consent for publication: Not Applicable.

Availability of data and materials: The datasets used and/or analysed during the current study are available from the corresponding author on reasonable request.

Competing interests: The authors declare that they have no conflict of interest.

Funding: This study is funded by the Natural Science Foundation of Guangdong Province (2016A030307035) and Natural Science Foundation of China (81801509). The funder had no role in the design of the study and collection, analysis, and interpretation of data and in writing the manuscript.

\section{Author contributions}

LYY conceptualized and designed the study, coordinated and supervised data collection, and reviewed and revised the manuscript. HY analyzed the data, drafted the initial manuscript, and revised the manuscript. FL collected the data, did the molecular analysis, and carried out the initial analyses. ZKC revised and polished the manuscript. LZ, JXX, YHW, JYG, YBM and JDL participated in the sample and data collection and performed the molecular analysis. All authors commented on previous versions of the manuscript. All authors read and approved the final manuscript. 
Acknowledgement: Not Applicable.

\section{References}

1. Kaplan M, Bromiker R, Hammerman C. Severe neonatal hyperbilirubinemia and kernicterus: are these still problems in the third millennium? Neonatology 2011; 100:354 - 62.

2. Keren R, Tremont K, Luan X, Cnaan A. Visual assessment of jaundice in term and late preterm infants. Arch Dis Child Fetal Neonatal Ed. 2009;94:F317-22.

3. Newman TB, Escobar GJ, Gonzales VM, Armstrong MA, Gardner MN, Folck BF. Frequency of neonatal bilirubin testing and hyperbilirubinemia in a large health maintenance organization. Pediatrics. 1999;104(5 Pt 2):1198203.

4. Dennery PA, Seidman DS, Stevenson DK. Neonatal hyperbilirubinemia. N Engl J Med. 2001;344:581-90.

5. Maisels MJ. Risk assessment and follow-up are the keys to preventing severe hyperbilirubinemia. J Pediatr (Rio J). 2011;39:275-6.

6. American Academy of Pediatrics Subcommittee on Hyperbilirubinemia. Management of hyperbilirubinemia in the newborn infant 35 or more weeks of gestation. Pediatrics. 2004;114:297-316.

7. Ho NK. Neonatal jaundice in Asia. Baillieres Clin Hematol. 1992;5:131-42.

8. Watchko JF, Daood MJ, Biniwale M. Understanding neonatal hyperbilirubinaemia in the era of genomics. Semin Neonatol. 2002;7:143-52.

9. Kadakol A, Ghosh SS, Sappal BS, Sharma G, Chowdhury JR, Chowdhury NR. Genetic lesions of bilirubin uridinediphosphoglucuronate glucuronosyltransferase (UGT1A1) causing Crigler-Najjar and Gilbert syndromes: Correlation of genotype to phenotype. Hum Mutat. 2000;16:297-306.

10. Canu G, Minucci A, Zuppi C, Capoluongo E. Gilbert and Crigler Najjar syndromes: an update of the UDPglucuronosyltransferase 1A1 (UGT1A1) gene mutation database. Blood Cells Mol Dis. 2013;50:273-80.

11. Huang MJ, Kua KE, Teng HC, Tang KS, Weng HW, Huang CS. Risk factors for severe hyperbilirubinemia in neonates. Pediatr Res. 2004;56:682-9.

12. Christensen RD, Lambert DK, Henry E, Eggert LD, Yaish HM, Reading NS, et al. Unexplained extreme hyperbilirubinemia among neonates in a multihospital healthcare system. Blood Cells Mol Dis. 2013;50:105-9.

13. Skierka JM, Kotzer KE, Lagerstedt SA, O'Kane DJ, Baudhuin LM. UGT1A1 genetic analysis as a diagnostic aid for individuals with unconjugated hyperbilirubinemia. J Pediatr. 2013;162:1146-52, 1152.e1-2.

14. Yang H, Wang Q, Zheng L, Zheng XB, Lin M, Zhan XF, Yang LY. Clinical Significance of UGT1A1 Genetic Analysis in Chinese Neonates with Severe Hyperbilirubinemia. Pediatr Neonatol. 2016;57:310-7.

15. Yang H, Wang Q, Zheng L, Lin M, Zheng XB, Lin F, Yang LY. Multiple Genetic Modifiers of Bilirubin Metabolism Involvement in Significant Neonatal Hyperbilirubinemia in Patients of Chinese Descent. PLoS One. 2015;10:e0132034.

16. Solé X, Guinó E, Valls J, Iniesta R, Moreno V. SNPStats: a web tool for the analysis of association studies. Bioinformatics. 2006;22:1928-9.

17. Subspecialty Group of Neonatology, Society of Pediatrics, Chinese Medical Association \& Chinese Multicenter Study Coordination Group for Neonatal Bilirubin Encephalopathy. Clinical characteristics of bilirubin encephalopathy in Chinese newborn infants-a national multicenter survey. Zhonghua Er Ke Za Zhi. 2012;50:3315. [Article in Chinese]. 
18. Chen Y, Wang HR, Zhou M, Li J. Correlation between serum IgG antibody titer of pregnant women with $\mathrm{O}$ blood type and hemolytic disease of newborn detected by micro-column gel agglutination assay: a meta-analysis. Maternal Child Health Care of China. 2019;34:2646. -8 [Article in Chinese].

19. Akanmu AS, Oyedeji OA, Adeyemo TA, Ogbenna AA. Estimating the risk of ABO hemolytic disease of the newborn in Lagos. Journal of Blood Transfusion 2015; 2015: 1-5.

20. Cao H, Wu R, Han M, Caldwell PHY, Liu JP. Oral administration of Chinese herbal medicine during gestation period for preventing hemolytic disease of the newborn due to $A B O$ incompatibility: A systematic review of randomized controlled trials. PLoS One. 2017;12:e0180746.

21. Long J, Zhang S, Fang X, Luo Y, Liu J. Association of neonatal hyperbilirubinemia with uridine diphosphateglucuronosyltransferase 1A1 gene polymorphisms: Meta-analysis. Pediatr Int. 2011;53:530-40.

22. Huang CS, Chang PF, Huang MJ, Chen ES, Hung KL, Tsou KI. Relationship between bilirubin UDPglucuronosyl transferase 1A1 gene and neonatal hyperbilirubinemia. Pediatr Res. 2002;52:601-5.

23. Zhou YY, Lee LY, Ng SY, Hia CP, Low KT, Chong YS, Goh DL. UGT1A1 haplotype mutation among Asians in Singapore. Neonatology. 2009;96:150-5.

24. Zhou Y, Wang SN, Li H, Zha W, Peng Q, Li S, Chen Y, Jin L. Quantitative trait analysis of polymorphisms in two bilirubin metabolism enzymes to physiologic bilirubin levels in Chinese newborns. J Pediatr. 2014;165:1154-60.

25. Yu Y, Du L, Chen A, Chen L. Study of Gilbert's Syndrome-Associated UGT1A1 Polymorphism in Jaundiced Neonates of ABO Incompatibility Hemolysis Disease. Am J Perinatol. 2019. doi:10.1055/s-0039-1688816.

26. Halis $\mathrm{H}$, Ergin $\mathrm{H}$, Köseler A, Atalay $\mathrm{E}$. The role of UGT1A1 promoter polymorphism andexon-1 mutations in neonatal jaundice. J Matern Fetal Neonatal Med. 2017;30:2658-64.

27. Watchko JF, Lin Z. Exploring the genetic architecture of neonatal hyperbilirubinemia. Semin Fetal Neonatal Med. 2010;15:169-75.

28. Lin YJ, Tsao PN. $211 \mathrm{G}$ to A variation of UGT1A1 and severe neonatal hyperbilirubinemia. Pediatr Neonatol. 2018;59:106-7.

29. Zhou Y, Wang SN, Li H, Zha W, Wang X, Liu Y, Sun J, Peng Q, Li S, Chen Y, Jin L. Association of UGT1A1 Variants and Hyperbilirubinemia in Breast-Fed Full-Term Chinese Infants. PLoS One. 2014;9:e104251.

30. Sato H, Uchida T, Toyota K, Kanno M, Hashimoto T, Watanabe M, et al. Association of breast-fed neonatal hyperbilirubinemia with UGT1A1 polymorphisms: 211G > A (G71R) mutation becomes a risk factor under inadequate feeding. J Hum Genet. 2013;58:7-10.

31. Farheen S, Sengupta S, Santra A, Pal S, Dhali GK, Chakravorty M, Majumder PP, Chowdhury A. Gilbert's syndrome: high frequency of the (TA)7 TAA allele in India and its interaction with a novel CAT insertion in promoter of the gene for bilirubin UDP-glucuronosyltransferase 1 gene. World J Gastroenterol. 2006;12:2269-75.

32. Huang CS, Luo GA, Huang ML, Yu SC, Yang SS. Variations of the bilirubin uridine-diphosphoglucuronosyl transferase 1A1 gene in healthy Taiwanese. Pharmacogenetics 2000;10:539 - 44.

\section{Figures}




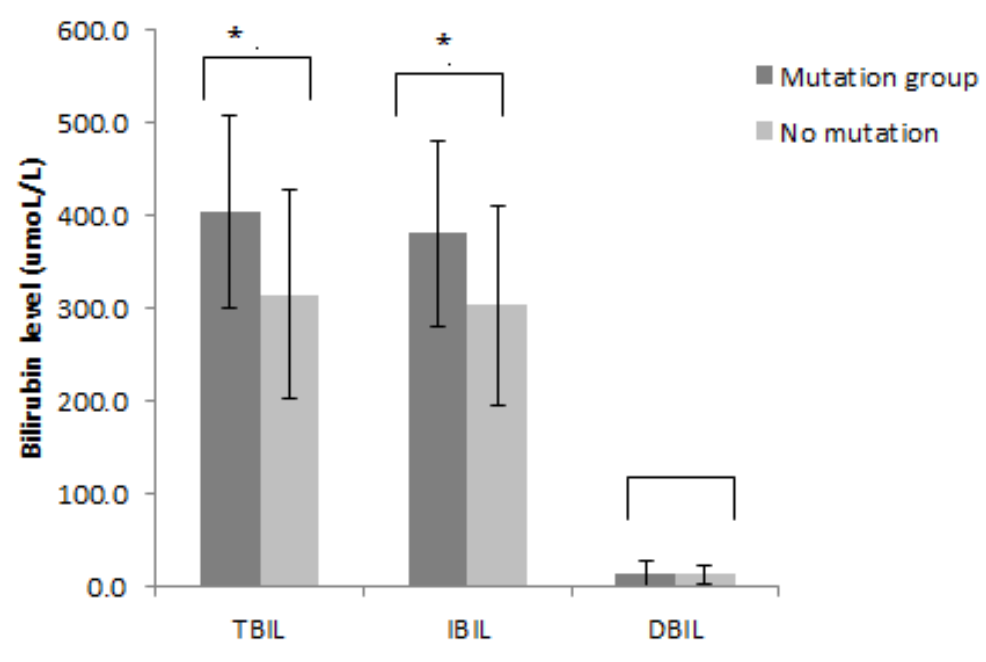

Figure 1

Distribution of serum bilirubin levels among the subgroup of the $A B O$ hemolytic disease neonates according to UGT1A1 c. 211 genotypes. 